\title{
Stochastic sensitivity analysis of glyphosate biochemical degradation
}

\author{
D. la Cecilia $^{a}$ and F. Maggia \\ ${ }^{a}$ Laboratory for Environmental Engineering, School of Civil Engineering, The University of Sydney, Bld. \\ J05, 2006 Sydney, NSW, Australia. \\ Email:_daniele.lacecilia@sydney.edu.au
}

\begin{abstract}
A comprehensive numerical modelling of soil biogeochemical dynamics allowed us to explore uncertainties in the fate of the herbicide glyphosate (GLP) and its crucial byproduct aminomethylphosphonic acid (AMPA) in soil. GLP and AMPA are both toxic and have the potential to disrupt complex ecological and biogeochemical processes. This study aims at identifying the more influential sources of uncertainty in GLP biochemical degradation.
\end{abstract}

Microorganisms may evolve different strategies for scavenging nutrients and energy from anthropogenic molecules depending on the surrounding environmental conditions. GLP can be catabolized by soil bacteria along two pathways. One biotic pathway produces AMPA, which can be degraded biologically to non-toxic end products, while a second biotic pathway produces non-toxic byproducts. Recent studies have shown that GLP and AMPA can also undergo fast chemical degradation to non-toxic byproducts in the presence of birnessite mineral, in which $\mathrm{Mn}^{3+}$ and $\mathrm{Mn}^{4+}$ ions act as catalysts. Therefore, a comprehensive GLP degradation reaction network was tested numerically by means of the BRTSim solver to assess GLP and AMPA degradation potential within a network that integrates several biochemical processes. Chemical and biological processes were described by Michaelis-Menten (MM) kinetics and the Monod growth model, respectively. The biochemical reactions describing the reaction network and the corresponding kinetic parameters were retrieved from the literature.

In this numerical study, GLP was applied at typical rates in a soil control volume representing the top soil of an agricultural plot. GLP and AMPA concentrations were modelled over time as a function of both biological and chemical processes. A suite of sensitivity analyses on input Michaelis-Menten-Monod (MMM) parameters were run to assess the effect of biological parametric uncertainties and to quantify the influence of specific biological processes or specific group of MMM kinetic parameters to the overall model output. Parameter values were randomly chosen from a Gaussian distribution with mean equal to the corresponding experimentally-retrieved parameter value and standard deviation equal to $5,10,15,20,25$, and $30 \%$ of that value.

We found that, in the lack of birnessite mineral, variability in the reaction rate constant increased GLP equilibrium concentration, while variability in the half-saturation concentration constant and the biomass yield decreased it. The action of birnessite mineral shrank output variability and decreased GLP concentrations by 5 times. Overall, the more GLP was biodegraded the more AMPA was produced, which accumulated due to its slow biodegradation.

Keywords: $\quad$ Glyphosate, AMPA, bio-degradation, Stochastic, Birnessite, Monod 


\section{INTRODUCTION}

The herbicide glyphosate (GLP) has been extensively used in agriculture (Benbrook, 2016) and evidence shows that this toxic compound can accumulate in soils and inland waters (Aparicio et al., 2013, Paris et al., 2013). Soil bacteria can degrade GLP along two pathways: one produces aminomethylphosphonic acid (AMPA, P1R1 and P1R1s, Figure 1) and the other produces sarcosine (SRC, P2R1s, Figure 1). Also AMPA is toxic but has only recently attracted attention in the scientific community, perhaps because GLP was more concerning or because of the lack of suitable analytical methods to distinguish AMPA from other compounds. Anyhow, the conditions allowing for AMPA production and its fate in the environment has to be understood. Some bacterial strains can biodegrade it to non-toxic byproducts (P1R2s, Figure 1) but this process occurs at a slow rate. In fact, also AMPA has been found in the environment (Struger et al., 2015, Paris et al., 2013). Li et al. (2015) and Paudel et al., (2015) have shown GLP and AMPA chemical degradation (P2R1c and P1R2c respectively, Figure 1) catalysed by $\mathrm{Mn}$ ions contained in birnessite mineral $\left(\left(\mathrm{Na}_{0.3} \mathrm{Ca}_{0.1} \mathrm{~K}_{0.1}\right)\left(\mathrm{Mn}^{3+}, \mathrm{Mn}^{4+}\right)_{2} \mathrm{O}_{4} \cdot 1.5 \mathrm{H}_{2} \mathrm{O}\right)$.

Since Liu et al. (1991), more and more comprehensive GLP degradation reaction networks have been developed, refined and included in numerical models to simulate GLP biodegradation and mass fluxes across the reaction network (Wang et al., 2016). Recently, la Cecilia \& Maggi (2017) published the most comprehensive GLP reaction network to date (Figure 1), which integrates GLP and AMPA biological and chemical degradation. This reaction network was integrated in the bioreactive numerical solver BRTSim (Maggi, 2015) and was used to numerically investigate the influence of the Michaelis-Menten-Monod (MMM) kinetic parameters (i.e., reaction rate constant $\mu\left(\mathrm{s}^{-1}\right)$, half-saturation concentration constant $K(\mathrm{M})$, and biomass yield coefficient $Y$ (mg-wet-Bio mol-Subs $\left.{ }^{-1}\right)$ to GLP and AMPA equilibrium concentrations.

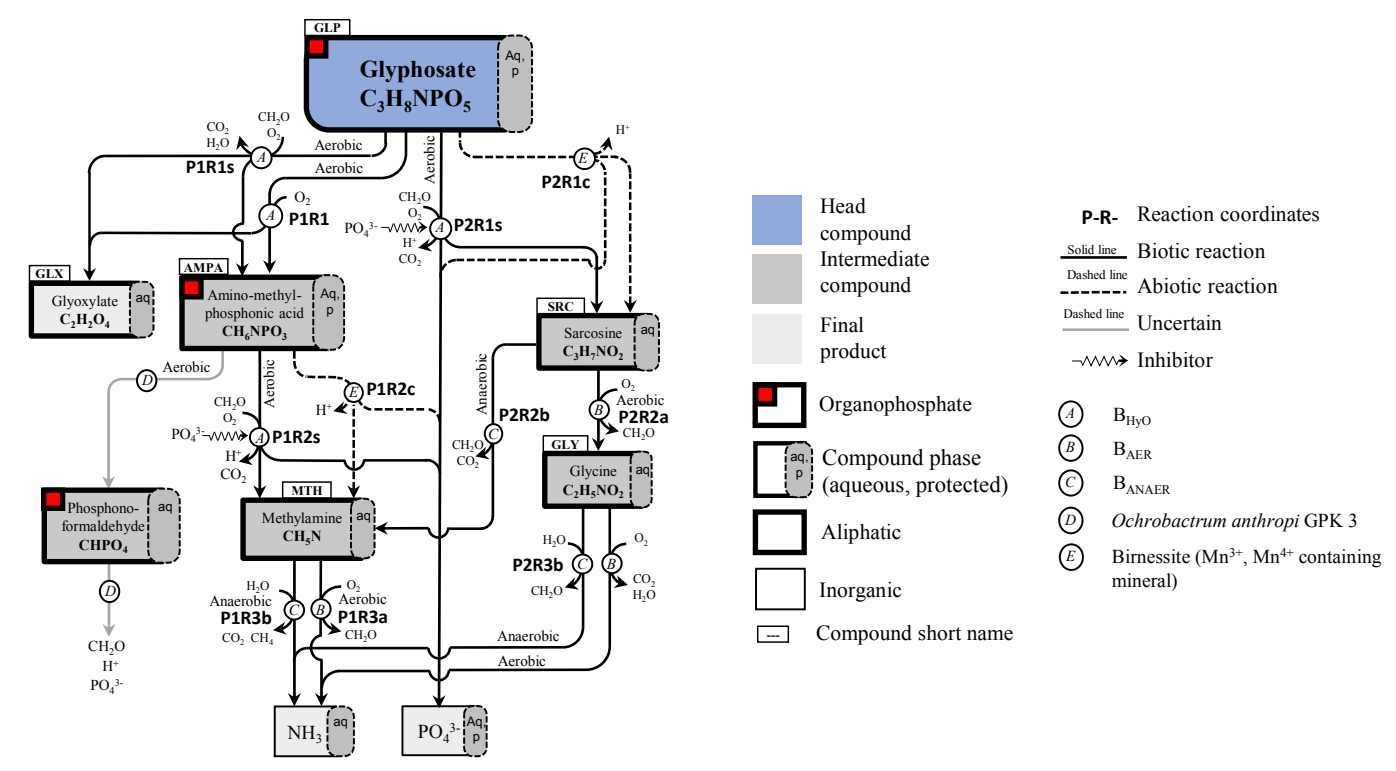

Figure 1. GLP biochemical degradation reaction network in soil from la Cecilia \& Maggi (2017). Extended biochemical reactions and the corresponding kinetic parameters are reported in Table 1.

\section{MATERIALS AND METHODS}

\subsection{GLP Reaction Network}

The biochemical reactions implemented in the numerical solver are reported in Table 1 together with their corresponding kinetic parameters. Both reactions and parameter values were estimated using published laboratory observations (Table 1) and the corresponding goodness-of-fit can be found in la Cecilia \& Maggi (2017). 
Table 1. Biochemical reactions implemented in the numerical solver together with their corresponding kinetic parameters as estimated in la Cecilia \& Maggi (2017) against laboratory observations published in (a) Balthazor and Hallas (1986); Jacob et al. (1988); (b) Moore et al. (1983); (c) Mcauliffe et al. (1990); (d) Balthazor and Hallas (1986); (e) Levering et al. (1981); (f) Hippe et al. (1979); (g) Appleyard and Woods (1956); (h) Hormann and Andreesen (1989); (i) Därre and Andreesen (1982); (l) $\mathrm{B}_{\mathrm{HyO}}$ was assumed to grow on $\mathrm{CH}_{2} \mathrm{O}$ as an independent reaction, with MMM kinetic parameters averaged from estimations against experiments in Balthazor and Hallas (1986); Jacob et al. (1988); Moore et al. (1983). B $\mathrm{B}_{\mathrm{HO}}$ encompasses Achromobacter Group V D, Agrobacterium radiobacter, Arthrobacter sp. GLP-1, Flavobacterium sp. GD1, Pseudomonas sp. LBr, and Pseudomonas PG2982; $\mathrm{B}_{\mathrm{AER}}$ encompasses Arthrobacter P1 and Pseudomonas Ovalis; $\mathrm{B}_{\mathrm{ANAER}}$ encompasses Clostridium purinolyticum, Methanosarcina barkeri and Eubacterium acidaminophilum. GLP $\left(\mathrm{C}_{3} \mathrm{H}_{8} \mathrm{NPO}_{5}\right)$; AMPA $\left(\mathrm{CH}_{6} \mathrm{NPO}_{3}\right)$; SRC $\left(\mathrm{C}_{3} \mathrm{H}_{7} \mathrm{NO}_{2}\right)$; Glyoxylate $\left(\mathrm{C}_{2} \mathrm{H}_{2} \mathrm{O}_{4}\right)$; Glycine $\left(\mathrm{C}_{2} \mathrm{H}_{5} \mathrm{NO}_{2}\right)$; Methylamine $\left(\mathrm{CH}_{5} \mathrm{~N}\right)$; Carbon source $\left(\mathrm{CH}_{2} \mathrm{O}\right)$. The order of $K$ values follows the order of carbon containing compounds in the corresponding biological reaction.

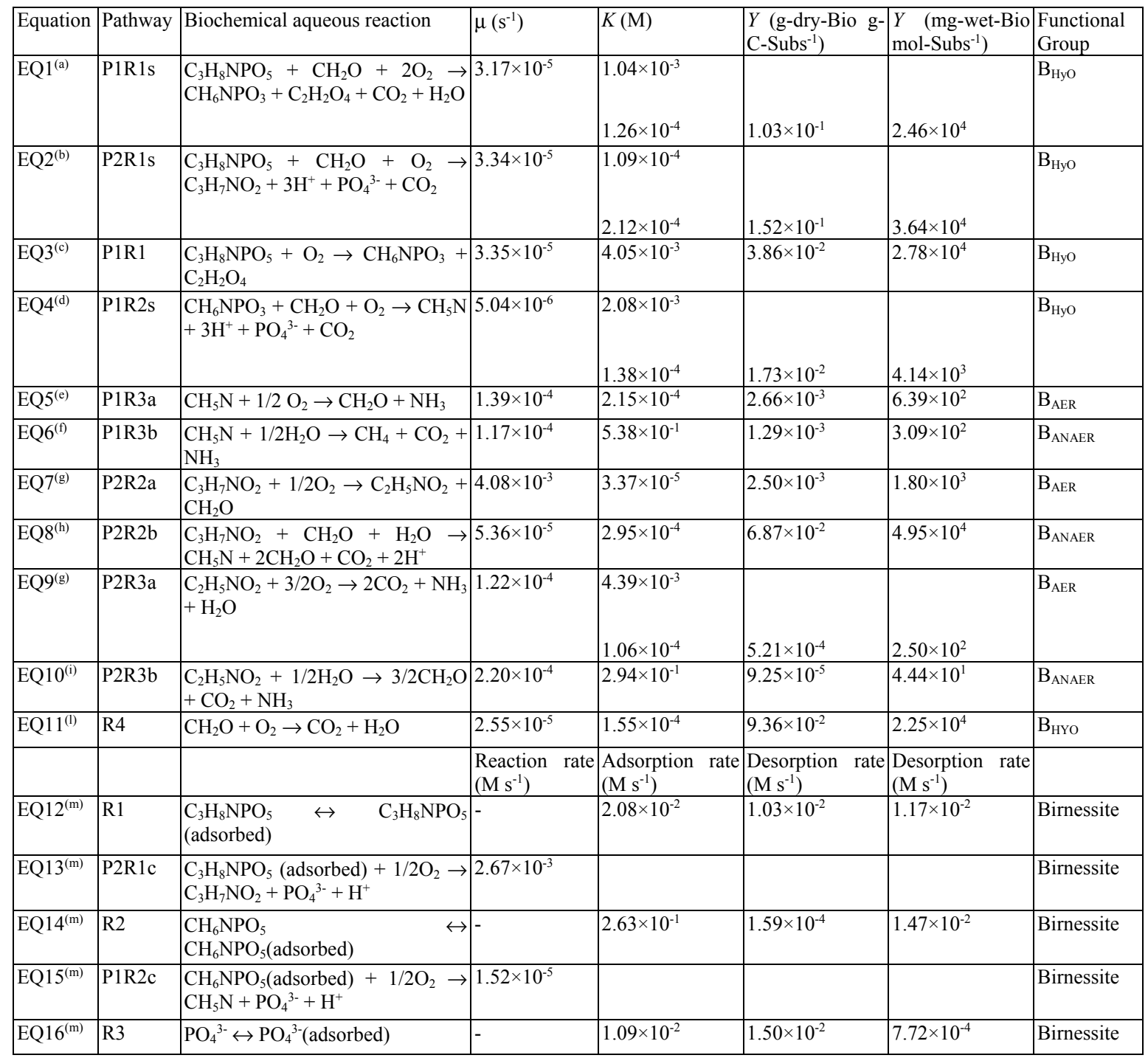

\subsection{Modelling}

The GLP reaction network was implemented in the general-purpose multiphase and multicomponent bioreaction transport solver BRTSim (Maggi, 2015) to predict GLP and AMPA equilibrium concentrations when the biochemical system was at steady-state in a soil control volume $V=1 \mathrm{~L}$. GLP at $0.003 \mathrm{M}$ concentration and an additional carbon source $\left(\mathrm{CH}_{2} \mathrm{O}\right)$ at $0.001 \mathrm{M}$ concentration were injected at a $Q=0.0036 \mathrm{~L} \mathrm{~h}^{-1}$ flow rate in an aqueous solution without and with birnessite mineral at $1.20 \mathrm{~g} \mathrm{~kg}_{\text {dry-soil }}{ }^{-1}$ concentration, with constant neutral $\mathrm{pH}$ and $\mathrm{O}_{2}$ levels equal to $3 \mathrm{mg} \mathrm{L}^{-1}$. 
Chemical degradation occurred only after GLP or AMPA absorbed onto birnessite (Li et al., 2015); adsorption was described by means of Langmuir kinetics (Langmuir, 1918), while degradation was described by means of MM kinetics. Using two separate experiments in the same laboratory conditions, Li et al. (2015) showed GLP and AMPA chemical degradation and measured the concentration of $\mathrm{PO}_{4}{ }^{3-}$ liberated by these two reactions. The release of $\mathrm{PO}_{4}{ }^{3-}$ was very quick with GLP, while it was 1 order of magnitude slower with AMPA. Although birnessite mineral can break GLP down to both AMPA and SRC, the very high rate at which $\mathrm{PO}_{4}{ }^{3-}$ concentration increased following GLP degradation might suggest that GLP was preferentially degraded to SRC (P2R1c, Figure 1). Therefore, it was assumed that GLP could only be degraded to SRC, and not to AMPA. Biological dynamics were accounted for by means of the Monod growth model (Bekins et al., 1998, Belser, 1989, Monod, 1949), in which the microbial functional group $\mathrm{B}_{\mathrm{HyO}}$ can grow on GLP and AMPA. The bacteria mortality rate $\delta\left(\mathrm{s}^{-1}\right)$ was assumed to be constant and equal to $10^{-6} \mathrm{~s}^{-1}$ after Gastrin and Marcetic (1968). Phosphate $\left(\mathrm{PO}_{4}{ }^{3-}\right)$ inhibitory effect on GLP and AMPA biodegradation along P1R1 and P1R2, respectively, was accounted for using an inhibition value $K_{I}=2.53 \times 10^{-4} \mathrm{M}$ estimated against observations in Balthazor and Hallas (1986). Substrate competition was not included in this work due to the limited variety of substrates available. $\mathrm{O}_{2}$ consumption in aerobic reactions was accounted for using a MM value $K=1.40 \times 10^{-5} \mathrm{M}$ after Button and Garver (1966), while an inhibition value $K_{I}=3.125 \times 10^{-6} \mathrm{M}$ was used for $\mathrm{O}_{2}$ inhibition on anaerobic processes. The $\mathrm{pH}$ effect on biological activity was accounted for by using a $K=10^{-9} \mathrm{M}$ for high $\mathrm{pH}$ and an inhibition value $K_{I}=$ $10^{-5} \mathrm{M}$ for low $\mathrm{pH}$, respectively, after Boon and Laudelout (1962).

\subsection{Analysis}

Simulations were run to determine whether a specific group of MMM kinetic parameters (i.e., $\mu, K$, or $Y$ ) or a specific biological reaction predominantly influenced GLP and AMPA equilibrium concentration (i.e. EQs 1 to 4). To this aim, the MMM kinetic parameters relative to one group and to EQs 1 to 4, were randomly chosen from a Gaussian distribution with mean equal to the corresponding experimentally retrieved parameter and standard deviation $(\sigma)$ equal to $5,10,15,20,25$, and $30 \%$ of that value, per each analysis. For the stochastic sensitivity analysis, 2000 simulations were run for each group and for each $\sigma$. The difference between GLP equilibrium concentration predicted in each model run $\left(\mathrm{GLP}_{\mathrm{c}, \mathrm{sto}}\right.$ and $\mathrm{GLP}_{\text {sto }}$, with and without birnessite respectively) and the concentration predicted using experimentally retrieved parameter values $\left(\mathrm{GLP}_{\mathrm{c}, \mathrm{ref}}\right.$ and $\mathrm{GLP}_{\text {ref, }}$, with and without birnessite respectively) was used as the sensitivity measure $\left(\mathrm{SM}_{\mathrm{c}, \mathrm{GLP}}=\mathrm{GLP}_{\mathrm{c}, \mathrm{sto}}\right.$ $\mathrm{GLP}_{\mathrm{c}, \text { ref }}$ and $\mathrm{SM}_{\mathrm{GLP}}=\mathrm{GLP}_{\text {sto }}$ - $\left.\mathrm{GLP}_{\mathrm{ref}}\right)$. The same approach was repeated for AMPA; therefore, the difference between AMPA equilibrium concentration predicted in each model run $\left(\mathrm{AMPA}_{\mathrm{c}, \mathrm{sto}}\right.$ and $\mathrm{AMPA} \mathrm{A}_{\mathrm{sto}}$, with and without birnessite respectively) and the concentration predicted using average parameter values (AMPA $A_{c, \text { ref }}$ and $\mathrm{AMPA}_{\text {ref }}$ ) was calculated as $\mathrm{SM}_{\mathrm{c}, \mathrm{AMPA}}=\mathrm{AMPA}_{\mathrm{c}, \text { sto }}-\mathrm{AMPA}_{\mathrm{c}, \text { ref }}$ and $\mathrm{SM}_{\mathrm{AMPA}}=\mathrm{AMPA}_{\text {sto }}-\mathrm{AMPA}_{\text {ref. }}$.

\section{RESULTS AND DISCUSSIONS}

\subsection{GLP and AMPA Equilibrium Concentrations}

GLP and AMPA equilibrium concentrations were reached within 100 simulated days. GLP, $\mathrm{P}_{\mathrm{c} \text { ref }}$ was nearly $7.4 \times 10^{-4} \mathrm{~g} \mathrm{~kg}_{\text {dry-soil }}{ }^{-1}$ (thin dashed black line in Figures 2a, c, and e), value in line with field data (Aparicio et al., 2013), while $\mathrm{GLP}_{\mathrm{c} \text {,sto }}$ ranged between $6.9 \times 10^{-4}$ and $7.8 \times 10^{-4} \mathrm{~g} \mathrm{~kg}_{\text {dry-soil }}{ }^{-1}$, with an average value of $7.4 \times 10^{-4} \mathrm{~g}$ $\mathrm{kg}_{\text {dry-soil }}{ }^{-1}$ (thick and thin solid black lines respectively in Figures 2a, c, and e). Concentrations were nearly 5 times higher and showed a more skewed and spread distribution when birnessite mineral was not present. AMPA $_{c, \text { ref }}$ was nearly $1.5 \times 10^{-3} \mathrm{~g} \mathrm{~kg}_{\text {dry-soil }}{ }^{-1}$ (thin dashed grey line in Figures $2 \mathrm{~b}, \mathrm{~d}$, and f), value in line with field data (Aparicio et al., 2013); AMPA $_{\mathrm{c}, \text { sto }}$ ranged between $1.6 \times 10^{-3}$ and $1.7 \times 10^{-3} \mathrm{~g} \mathrm{~kg}_{\text {dry-soil }}{ }^{-1}$, with an average value of $1.5 \times 10^{-3} \mathrm{~g} \mathrm{~kg}_{\text {dry-soil }}{ }^{-1}$ (thick and thin solid grey lines respectively in Figures $2 \mathrm{~b}$, d, and f). These concentrations are higher than those modelled for GLP, highlighting that produced AMPA was slowly biodegraded and suggesting that AMPA can be a more concerning pollutant than GLP in the environment. In the lack of birnessite, AMPA concentrations increased by 40 times, but their frequency distribution was less spread. GLP and AMPA distribution skewness was opposed, meaning that (1) GLP biodegradation to AMPA rather than SRC was the preferential pathway in the reaction network as the more GLP was degraded the more AMPA was produced, and (2) AMPA was slowly degraded.

The parameters space corresponding to the 4 input variables was assumed to be adequately sampled by 2000 simulations, and an increasing variability for each parameter group revealed interesting results (Figure 3). 
Chemical and biological processes collaborated to fast degrade GLP. Lower $\mu$ resulted in slower biodegradation rates, which were flanked by the catalytic action of birnessite mineral. The lowest $\mu$ values caused the mineral surface to become saturated; therefore, GLP concentration started to increase. In the lack of birnessite, the increasing variability in $\mu$ resulted in a nonlinear increase in GLP concentration. Biotic processes alone could fast degrade GLP; low $\mu$ resulted in a substantial increase in GLP concentration, while high $\mu$ did not substantially decrease it. Increasing variability in $K$ resulted in lower GLP concentration both with and without birnessite. This is because GLP application concentration was similar to $K$; low $K$ substantially increased the biodegradation rate, while high $K$ did not decrease it likewise. Similarly, increasing variability in $Y$ resulted in lower GLP concentration. In the presence of birnessite, bacteria consumed small amounts of substrate; therefore, varying $Y$ did not substantially affect GLP. In the lack of birnessite, high $Y$ resulted in an offset between a slower degradation rate but a higher biomass concentration; conversely, low $Y$ resulted in faster rates but lower biomass concentration. Therefore, GLP concentration did not change in average.

We acknowledge that other envirnmental conditions including $\mathrm{pH}$, and $\mathrm{O}_{2}, \mathrm{CH}_{2} \mathrm{O}$, and birnessite availability can affect these results. These effects werw investigated in a comprehensive in-silico analysis in la Cecilia \& Maggi (2017).
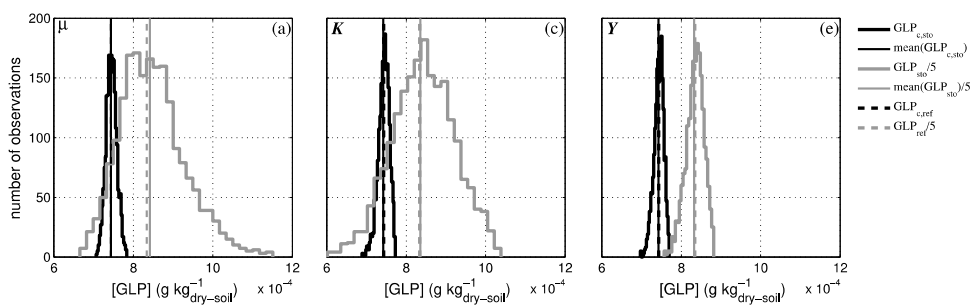

Figure 2. Distribution of $\mathrm{GLP}_{\mathrm{c}, \text { sto }}$ and $\mathrm{GLP}_{\text {sto }}$ around $\mathrm{GLP}_{\mathrm{c}, \mathrm{ref}}$ and

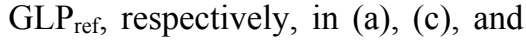
(e) and $\mathrm{AMPA}_{\text {csto }}$ and $\mathrm{AMPA}_{\text {sto }}$ around $\mathrm{AMPA}_{\mathrm{c}, \mathrm{ref}}$ and $\mathrm{AMPA}_{\mathrm{ref}}$, respectively, in (b), (d), and (f). $\sigma=$ $10 \%$. Number of bins were chosen
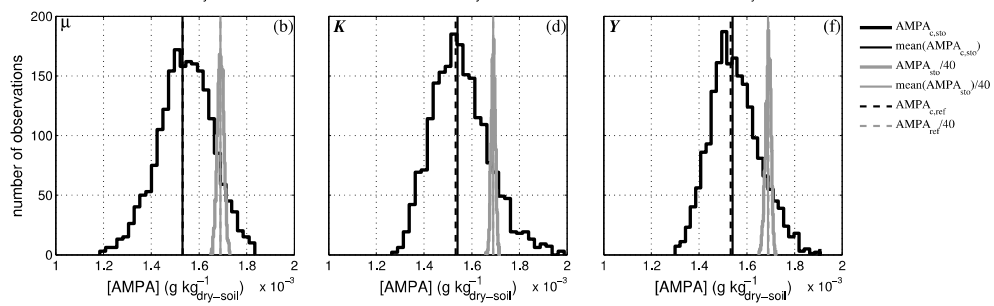
according to Freedman-Diaconis' rule.
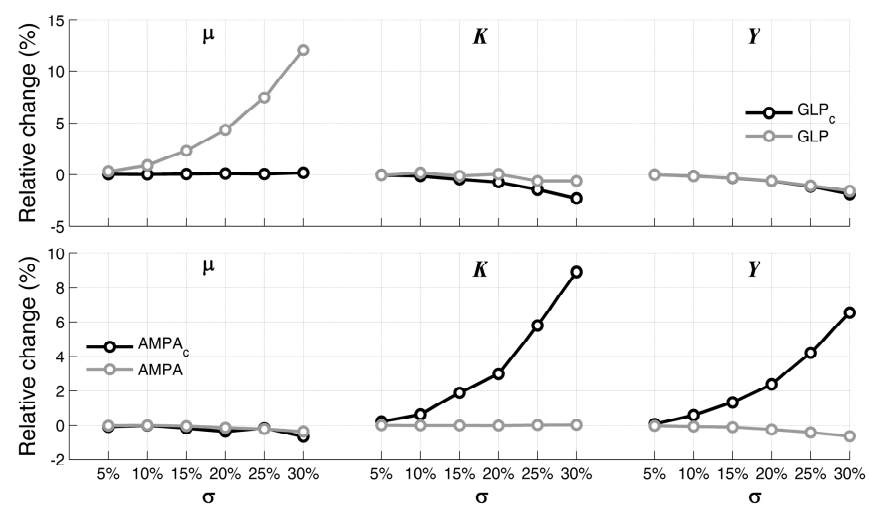

Figure 3. Relative change in $\mathrm{GLP}_{\mathrm{c} \text {,sto }}$ and $\mathrm{GLP}_{\text {sto }}$ with respect to $\mathrm{GLP}_{\mathrm{c} \text {,sto }}$ and $\mathrm{GLP}_{\text {ref, }}$, respectively, as a function of $\sigma$ in the upper panel; relative change in $\mathrm{AMPA}_{\mathrm{c} \text {,sto }}$ and $\mathrm{AMPA}_{\text {sto }}$ with respect to $\mathrm{AMPA}_{\mathrm{c}, \text { ref }}$ and $\mathrm{AMPA}_{\text {ref, respectively, as a function }}$ of $\sigma$ in the lower panel.

\subsection{Sensitivity measure}

Reaction P1R1 (Table 1, EQ3) mostly drove the GLP reaction network because the average of SM chLP $_{\text {GL }}$ $\mathrm{SM}_{\mathrm{GLP}}$ substantially changed as the parameter values relative to EQ3 changed (red horizontal lines in Figure 4a and c, boxplots in $3^{\text {rd }}, 7^{\text {th }}$, and $11^{\text {th }}$ column); P1R1s contributed little to the reaction network, while P2R1s and P1R2s did not affect the reaction network (Figure $4 \mathrm{a}$, boxplots in $1^{\text {st }}, 2^{\text {nd }}$, and $4^{\text {th }}$ column, respectively). Results from EQ3 showed that higher $\mathrm{GLP}_{\mathrm{c} \text {,sto }}$ (therefore greater positive $\mathrm{SM}_{\mathrm{c}, \mathrm{GLP}}$ ) resulted from lower $\mu$ values (or high $K$ or $Y$ values, Figure $4 \mathrm{a}$ ) and corroborated that $Y$ did not affect $\mathrm{GLP}_{\text {sto }}$, that is when there was no birnessite mineral (Figure $4 \mathrm{c}, 9^{\text {th }}$ to $12^{\text {th }}$ column). 
EQ3 also decreased the model output variability as indicated by the smaller $\mathrm{SM}_{\mathrm{c}, \mathrm{GLP}}$ and $\mathrm{SM}_{\mathrm{GLP}}$ range for EQ3 compared to those relative to EQs 1, 2, and 4 (Figure $4 \mathrm{a}$ and c).

EQ4 influenced the least the reaction network. In fact, this reaction involves AMPA biodegradation, which poorly contributes to GLP biodegraders growth (i.e., $Y$ relative to AMPA is 1 order of magnitude lower than $Y$ relative to GLP as reported in Table 1) and occurs at a slow rate (Figure $4 \mathrm{~b}$ and $\mathrm{d}$ ). GLP biodegradation to AMPA described by EQ3 was found to be the most important regulatory process on the reaction network; therefore, it was expected that EQ3 influenced $\mathrm{SM}_{\mathrm{c}, \mathrm{AMPA}}$ and $\mathrm{SM}_{\mathrm{AMPA}}$ as well. A faster AMPA production was not followed by the same increase in AMPA degradation rate, thus it accumulated. In the event that microorganisms show GLP degradation towards AMPA, then AMPA would pose an even more serious risk to the environment.
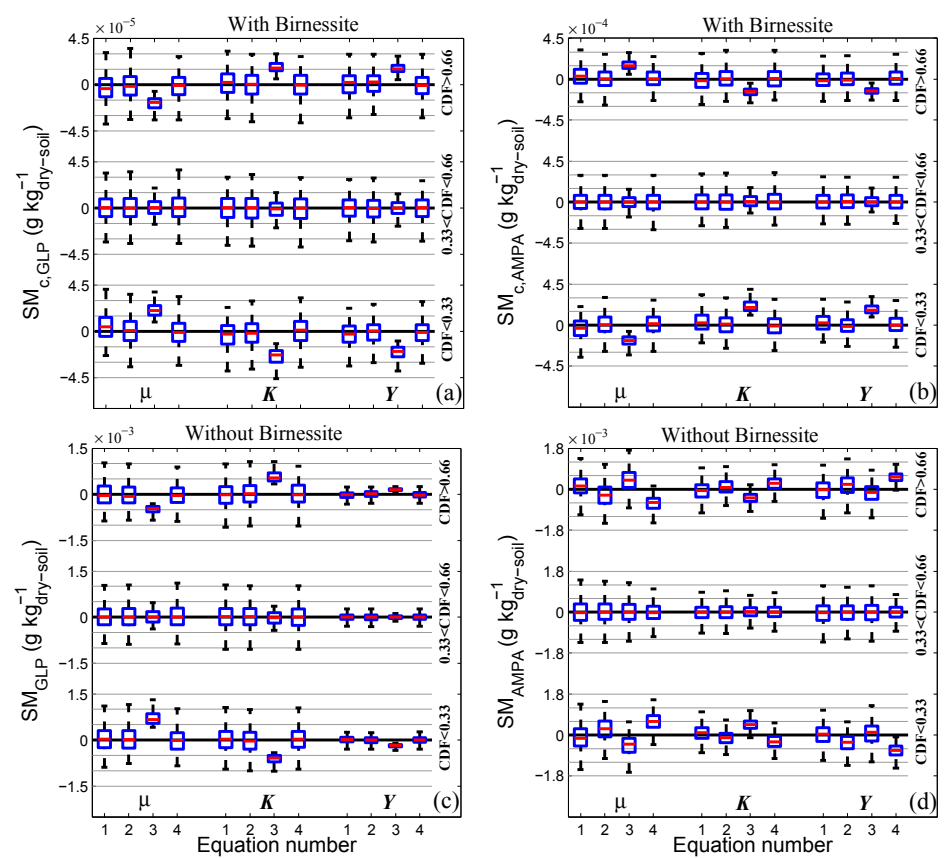

Figure 4. Boxplot showing the outcome variability in $\mathrm{SM}_{c, G L P}$ (a), $\mathrm{SM}_{\mathrm{GLP}}(\mathrm{c}), \mathrm{SM}_{\mathrm{c}, \mathrm{AMPA}}(\mathrm{b})$, and $\mathrm{SM}_{\mathrm{AMPA}}$ (d), grouped horizontally by parameter quantiles (i.e., Q1 $=33^{\text {th }}$ and Q2 = $66^{\text {th }}$ ) and vertically by MMM kinetic parameter, and organized by equation number. Black horizontal lines indicate $\quad \mathrm{SM}_{\mathrm{c}, \mathrm{AMPA}}, \quad \mathrm{SM}_{\mathrm{c}, \mathrm{AMPA}}$, $\mathrm{SM}_{\mathrm{c}, \mathrm{AMPA}}$, and $\mathrm{SM}_{\mathrm{c}, \mathrm{AMPA}}$ equal to $0 . \sigma$ $=10 \%$.

\section{CONCLUSIONS}

A complex GLP biochemical degradation reaction network was presented and the influence of biochemical processes to GLP and AMPA degradation were quantified. GLP oxidation to AMPA described by EQ3 resulted to be the most significant biotic process regulating GLP to AMPA mass flux. Birnessite mineral availability substantially influenced their equilibrium concentration and reduced their outcome variability. This work suggested that all kinetic parameters (i.e., $\mu, K$, and $Y$ ) are important descriptors of biological processes within a complex reaction network and may cause different responses. For example, an increasing variability in $\mu$ resulted in a higher average GLP concentration (up to $+12 \%$ than the reference concentration), while an increasing variability in $K$ and $Y$ resulted in higher average AMPA concentrations (up to $+9 \%$ and $+7 \%$ than the reference concentration, respectively). Yet, AMPA concentration was nearly twice than GLP concentration; therefore, it is suggested that AMPA is an emerging contaminant in the environment. It is advisable to put effort into AMPA monitoring campaigns to collect data on its level of contamination for consideration in future regulation initiatives.

\section{ACKNOWLEDGMENTS}

This research was partly funded by the Sydney Research Excellence Initiative (SREI 2020) of The University of Sydney. The authors acknowledge the University of Sydney HPC service at The University of Sydney (http://sydney.edu.au/research_support/). The BRTSim solver package can be downloaded at the link https://www.dropbox.com/sh/wrfspx9f1dvuspr/AAD5iA9PsteX3ygAJxQDxAy9a?dl=0.

The author acknowledges the Postgraduate Research Support Scheme of The University of Sydney for funding for travel to, attendance at, and participation in MODSIM2017. 


\section{REFERENCES}

Aparicio, V.C., De Gerónimo, E., Marino, D., Primost, J., Carriquiriborde, P. and Costa, J.L. (2013). Environmental fate of glyphosate and aminomethylphosphonic acid in surface waters and soil of agricultural basins. Chemosphere, 93, 1866-1873.

Appleyard, G. and Woods, D.D. (1956). The pathway of creatine catabolism by Pseudomonas ovalis. Journal of General Microbiology, 14(2), 351-65.

Balthazor, T.M. and Hallas, L.E. (1986). Glyphosate-degrading microorganisms from industrial activated sludge. Applied and Environmental Microbiology, 51(2), 432-434.

Bekins, B., Warren, E. and Godsy, E. (1998). A comparison of zero-order, first-order and Monod biotransformation models. Ground Water, 261-268.

Belser, L.W. (1989). Population ecology of nitrifying bacteria. Annual Review of Microbiology, 309-333.

Benbrook, C.M. (2016) Trends in glyphosate herbicide use in the United States and globally. Environmental Sciences Europe, 1-15.

Boon, B. and Laudelout, H. (1962). Kinetics of nitrite oxidation by Nitrobacter Winogradskyi. Biochemical Journal, 440-447.

Button, D.K. and Garver, J.C. (1966). Continuous Culture of Torulopsis utilis: A Kinetic Study of Oxygen Limited Growth. Journal of General Microbiology, 45, 195-204.

Därre, P. and Andreesen, J.R. (1982). Selenium-dependent Growth and Glycine Fermentation by Clostridium purinolyticum. Journal of General Microbiology, 128, 1457-1466.

Gastrin B., Kallings, L.O. and Marcetic, A. (1968). The survival time for different bacteria in various transport media. Acta Pathologica Microbiologica Scandinavica, 371-380.

Hippe, H., Caspari, D., Fiebig, K. and Gottschalk, G. (1979). Utilization of trimethylamine and other Nmethyl compounds for growth and methane formation by Methanosarcina barkeri. Proceedings of the National Academy of Sciences of the United States of America, 76(1), 494-498.

Hormann, K. and Andreesen, J.R. (1989). Reductive cleavage of sarcosine and betaine by Eubacterium acidaminophilum via enzyme systems different from glycine reductase. Archives of Microbiology, 153(1), 50 59.

Jacob, G.S., Garbow, J.R., Hallas, L.E., Kimack, N.M., Kishore, G.M. and Schaefer, J. (1988). Metabolism of glyphosate in Pseudomonas sp. strain LBr. Applied and Environmental Microbiology, 54(12), 2953-2958.

la Cecilia, D. and Maggi, F. (2017) A review on glyphosate degradation in a soil microcosm. Environmental Pollution, (in press)

Levering, P.R., Dijkhuizen, L. and Harder, W (1984). Metabolic regulation in the facultative methylotroph Arthrobacter P1. Growth on primary amines as carbon and energy sources. Archives of Microbiology, 139, 188-195.

Li, H., Joshi, S.R. and Jaisi, D.P. (2015). Degradation and Isotope Source Tracking of Glyphosate and Aminomethylphosphonic Acid. Journal of Agricultural and Food Chemistry, 64, 529-538.

Langmuir, I. (1918) The adsorption of gases on plane surfaces of glass, mica and platinum. Journal of American Chemical Society, 40(9), 1361-1403.

Liu, C.M., McLean, P.A., Sookdeo, C.C. and Cannon, F.C. (1991). Degradation of the Herbicide Glyphosate by Members of the Family Rhizobiaceae. Applied and Environmental Microbiology, 57(6), 1799-1804

Maggi, F. (2015). BRTSim version 1; A general-purpose multiphase and multicomponent computational solver for biogeochemical reaction-advection-dispersion processes in porous and non-porous media, First edition, Research Report R954, The University of Sydney, Australia, pp 29.

Mcauliffe, K.S., Hallas, L.E. and Kulpa, C.F. (1990). Glyphosate degradation by Agrobacterium radiobacter isolated from activated sludge. Journal of Industrial Microbiology, 6, 219-221.

Monod, J. (1949). The Growth of Bacterial Cultures. Annual Review of Microbiology, 371-394.

Moore, J.K., Braymer, H.D. and Larson, A.D. (1983). Isolation of a Pseudomonas sp. which utilizes the phosphonate herbicide glyphosate. Applied and Environmental Microbiology, 46(2), 316-320.

Paudel, P., Negusse, A. and Jaisi, D.P. (2015). Birnessite-Catalyzed Degradation of Glyphosate: A Mechanistic Study Aided by Kinetics Batch Studies and NMR Spectroscopy. Soil Science Society of America Journal, 79, 815-825.

Pietro, P., Citro, L., Di Carlo, E., Maschio, G., Pace, E. and Ursino, S. (2013). Rapporto nazionale pesticide nelle acque dati 2009-2010. ISPRA. Rapporti 175. ISBN 978-88-448-0595-1. pp 82.

Struger, J., Van Stempvoort, D.R. and Brown, S.J. (2015). Sources of aminomethylphosphonic acid (AMPA) in urban and rural catchments in Ontario, Canada: Glyphosate or phosphonates in wastewater? Environmental Pollution, 204, 289-297.

Wang, S, Seiwert, B., Kästner, M., Miltner, A., Schäffer, A., Reemtsma, T., Yang, Q and Nowak, K.M. (2016). (Bio)degradation of glyphosate in water-sediment microcosms - A stable isotope co-labeling approach. Water Resources, 99, 91-100. 